\title{
RNA Interference for Viral Infections
}

Stephen J. Blake, Fawzi F. Bokhari and Nigel A. J. McMillan

Australian Infectious Diseases Research Centre and Diamantina Institute, University of Queensland, Brisbane, Qld 4072, Australia

\section{Introduction}

While the advent of antibiotics heralded a major victory over the microbial world, at least in the form of bacteria, and has saved countless millions of lives, we have not had the same success when it comes to viruses. The nature of viruses as intracellular parasites which have evolved to be completely reliant on host cells for their replication has meant that developing virus-specific drugs represents a unique challenge. Indeed, one only has to look at the short list of currently available antivirals to realise that this is an area of need and one in which we have had only modest success. Even with the resources and effort that went into developing antiHIV therapies we have only managed to turn this previously untreatable infection into one that is chronic and clinically manageable. It is sobering to realise that no cure for HIV appears likely in the near future.

Viruses have not had it all their own way of course. Immunisation is clearly the most successful means developed to date to combat viral infections and this has led to the complete eradication of smallpox (1), hopefully soon to be followed by polio, although this is proving more difficult (2). The recent introduction of the vaccine 
against cervical cancer, a disease caused by human papillomavirus, is the latest example of viral vaccine success with the most recent data suggesting rates of precancerous lesions are falling in target populations since its introduction $(3,4)$. However, vaccines do not exist for most viral infections. Moreover, there are situations where immunisation is either inadequate or has proven to be ineffective, or in some cases dangerous. For example, vaccines against HIV have not been successful despite enormous efforts and resources (5). Early RSV vaccines generated poor immune responses that not only did not prevent infection, they made subsequent infections even worse (6). Furthermore, vaccination is ineffective for viruses that replicate actively in sites of immune privilege, such as the CNS (e.g. Herpes virus family), or attack the immune system itself (HIV).

Anti-viral drugs, on the other hand, would potentially work in such situations but are available for only a limited number of viruses. We have highly effective anti-viral therapies against HIV which, while not curing the virus, allow it to become a clinically manageable chronic infection. Anti-influenza medications such as Tamifluß (Oseltamivir) and Relenza ${ }^{\circledR}$ (Zanamivir) have recently been developed (7) which are useful in the acute hospital setting but are limited in general use due to the inability to rapidly identify patients with flu (rather than a range of other respiratory viruses) and that fact that patients often present to physicians at a late stage of infection where recovery is only improved by as little as 24 hours.

While much effort has been made to develop new antivirals via natural product or small molecule screens, success has been time-consuming, fortuitous and difficult to obtain. The problem lies in the fact that viruses use much of our own cellular machinery to complete their replication cycle, making specificity a major hurdle. 
Clearly new approaches are required to allow us to rapidly identify novel antiviral drug targets not only within the virus itself but also within the host cell and it is here that RNA interference offers exciting new possibilities. RNA interference, or RNAi, is a means by which one can achieve the silencing of single genes within a cell via the introduction of small double-stranded RNA molecules in the form of short-interfering RNA (siRNA) or short-hairpin RNA (shRNA) $(8,9)$. RNAi was discovered in the mid1990s firstly in the plant field where Jorgensen described co-suppression or posttranslational gene silencing (10). The mechanisms were later expanded upon and explained independently by the laboratories of Baulcombe and Waterhouse $(11,12)$. While initially thought to be limited to plants, it was soon discovered by Fire and Mello that RNAi would work in nematodes (9), a discovery for which they were awarded the Nobel Prize in 2006. The importance of RNA interference in the viral setting was quickly realised with the discovery that exogenously delivered synthetic siRNA was a powerful means to knock down viral gene expression, with HIV one of the first targets where RNAi was shown to work (13). It offered a viral-specific therapy to limit or prevent infection. Indeed it has been speculated that the evolutionary role of RNAi was in the cellular defence against viruses and the silencing of transposable elements by the generation of virus-specific siRNA's (14).

In this review we will outline the role of RNAi as a direct therapy against viral infections as well as cancer caused by viral infections. We will review efforts using RNAi in genome-wide knockout studies to identify previously unthought-of and novel anti-viral drug targets that will allow the development of new classes of anti-viral drugs as well as to re-purpose some drugs currently in the clinic but for which an anti-viral use has not previously been realised. 


\section{RNAi as a therapy for viruses}

RNAi is ideal for use against viruses due to viruses' dependence on a limited set of genes, high levels of replication and targets that can be non-host genes. Additionally, the development time for new siRNA is comparatively short compared to other specific drugs, such as small molecule inhibitors, meaning siRNA against newly isolated viruses or to combat siRNA resistant mutations can be rapidly developed. An alternative strategy is to target host genes that are critical for viral lifestyle, such as surface receptors required for cell entry (e.g. CCR5 in HIV) or host genes involved in viral replication.

While RNAi has been astonishingly potent at blocking the replication of many viruses in vitro, the efforts to design in vivo and clinical therapies have been less successful. The main issues preventing effective in vivo therapies revolve around effective delivery to target cells, an issue that is seen as the major obstacle to developing clinical siRNA. The liver is an excellent target for siRNA therapy with many different groups showing siRNA-loaded nanoparticles distribute in high concentrations to the liver following intravenous delivery. This has spawned?? development of siRNA therapies for HCV, HBV as well as various liver cancers and cholesterol metabolism. Respiratory viruses have been shown to be well controlled by intranasal delivery of siRNA in mice, with delivery here beneficial in that it avoids potential complications following systemic drug delivery. SiRNA has been shown to be effective at treating a diverse range of viruses (Table 1). There are two possible strategies for using siRNA as a therapy for viruses - direct targeting of viral genes or downregulation of host genes required for virus replication.

TABLE 1. Examples of siRNAs used to treat virus infections. 


\begin{tabular}{|c|c|c|}
\hline Virus & Genes targeted & References \\
\hline Influenza A & $\begin{array}{l}\text { Nucleoprotein } \\
\text { Acidic polymerase }\end{array}$ & $(15-17)$ \\
\hline SARS coronavirus & $\begin{array}{l}\text { Spike protein } \\
\text { NSP-12 } \\
\text { M protein }\end{array}$ & $(18-21)$ \\
\hline Human Papilloma Virus & $\begin{array}{l}\text { E6 } \\
\text { E7 }\end{array}$ & $(22-24)$ \\
\hline Epstein Barr Virus & EBNA1 & $(25,26)$ \\
\hline Ebola Virus & Polymerase (L) gene & $(27,28)$ \\
\hline
\end{tabular}

\subsection{Direct inhibition of viral genes by siRNA}

RNAi inhibition of viral genes has been highly successful, with RSV, HBV, HIV, and Influenza virus able to be strongly inhibited in cell culture and small animal models. Target selection for RNAi centres around genes critical for viral survival, replication, or cell infection. Unlike conventional drugs, RNAi can target any genes, including previously undruggable proteins such as transcription factors. Translation of these successes to clinical trials has been slow, with two trials recently completed and numerous more underway.

\section{Respiratory Syncytial Virus (RSV)}

Some of the earliest and most promising studies using siRNA were targeting RSV. RSV infection is a major cause of seasonal colds, which contribute a large cost to the public health system and can be deadly to patients with compromised immune systems, such as the elderly or infants $(29,30)$. With no vaccine, it is also ideal to test novel therapies such as siRNA. RSV represents the most developed study of RNAi against viruses, with the completion of a phase 2 clinical trial. The results of two animal studies were published in 2005 using different approaches to treat RSV $(31,32)$. The first by Zhang et al $(31)$ used siRNA to target the viral gene NS1 which is essential for viral replication (33), and has been implicated in dampening host 
immune responses to virus (34). In this study, RNAi was in the form of shRNAs encoded on plasmids and delivered by lipofectamine, and was shown to inhibit viral replication in cultures. When delivered intranasally by nanoparticles (TransGenex Nanobiotech Inc), viral replication and disease was limited in both prophylactic and therapeutic manners, with increased anti-viral immune responses observed. The second mouse study used siRNAs against RSV-P protein that were designed in an earlier in vitro study (35). This study delivered siRNA intranasally before challenge with RSV and was able to show a substantial reduction in viral load and clinical symptoms in the mice (32). There was also a therapeutic effect, as delivering siRNA up to 3 days post-infection still caused a decrease in symptoms and viral load. Most siRNA were delivered using TransIT-TKO vector, however they were surprisingly able to show naked siRNA to have comparable efficacy. Additionally the results were seen without the induction of IFN- $\alpha$ and were not observed to inhibit a related Pneumovirus, leading to the conclusion that direct inhibition of viral genes and not immune activation was the cause for virus inhibition.

The successes of these studies led to the development by Anylam of AALN-RSV01, a 19 b.p. siRNA which targets the RSV nucleocapsid-protein gene and potently blocks RSV replication in vitro. After passing phase 1 clinical trials (36) the group extended into a phase 2 clinical trial to study the drug's efficacy (37). The siRNA was delivered via saline inhalation with most study participants receiving multiple doses from day -1 through to +3 relative to challenge with RSV culture. While the siRNA treatment had a modest effect on reducing the total number of patients infected, it had no significant impact on viral load or any of the measured patient symptoms. The delivery of this siRNA may be key as naked siRNA was used, possibly being 
trapped in the upper airways, unable to reach the viral infected cells. While naked siRNA was shown effective in mouse models (32), the respiratory tract of humans is significantly different than rodents, who are obligate nasal breathers. Despite the very modest therapeutic effect, this study has demonstrated that nasally administered siRNA are well tolerated in humans and can have an impact on respiratory viral growth.

Hepatitis $B$ Virus (HBV)

Despite the availability of a preventative vaccine (38), HBV is still a very common chronic infection, with 350 million people infected worldwide, and is a leading cause of the liver cancer hepatocellular carcinoma (39). HBV replicates almost exclusively within hepatocytes, an ideal target for siRNA therapy as liver uptake of siRNA encapsulated in liposomes or other nanoparticles is extremely high $(40,41)$. Early results demonstrated that HBV replication in culture (42) or in a mouse model (43) was strongly inhibited by siRNA directed against HBV core and surface antigens, respectively. Some of the most promising anti-HBV siRNA delivery has been seen with a modified lipid know as a stable nucleic acid lipid particle (SNALP), which has a longer half-life in serum than normal lipids and is specifically designed to deliver siRNA to the liver (44). Using siRNA that were modified to improve in vivo stability (45) and encapsulated in SNALPs, the group administered therapy i.v. in a mouse model of HBV (45). The results were highly promising, with multiple doses able to induce a $>1$ log reduction in circulating HBV DNA. Long term reduction in viral titres out to 7 days were observed following a single treatment, and the group was also able to maintain viral suppression when dosing mice weekly with siRNA. The modified siRNA were also shown to have an improved toxicity profile and did not 
induce immune responses when tested against unmodified siRNA. Stable delivery of shRNA by adeno-associated viruses has been proposed as an alternative delivery and has been shown to be safe and effective at reducing HBV viral load in vivo (46, 47). While these vectors may achieve more stable gene knockdown, safety concerns compared to non-viral vectors may limit their clinical use. All the aforementioned studies used HBVsAg as a target. Overall, siRNA against HBV seems an attractive approach, however clinical development has been slow, with only a phase I trial conducted to date (48). In this trail plasmid encoded shRNA against 4 different HBV subtypes was able to be delivered to patients safely however to only modest effect against HBV and evidence of an anti siRNA immune response.

\subsection{Targeting human genes to limit viral replication}

Targeting human genes is an attractive option when viruses have high rates of mutations so can quickly develop resistance against siRNA. While care is required when targeting host genes as to not disrupt any critical normal functions, this field is blossoming due to recent successes at siRNA inhibition of HIV and HCV, two of the most serious chronic viral infections.

Hepatitis $\mathrm{C}$ virus $(\mathrm{HCV})$

The development of siRNA for HCV is one of the most novel in the antiviral field. Like $\mathrm{HBV}, \mathrm{HCV}$ is a chronic viral infection of the liver, with an estimated 200 million people infected worldwide and an increasing cause of hepatocellular carcinoma (49). HCV has a very complicated lifecycle and the discovery of microRNA uncovered a novel host target to inhibit viral replication. Early gene expression studies showed a high level of expression of the microRNA, mir-122, in the liver (50), and this was 
implicated in lipid metabolism and cholesterol production $(51,52)$. Interestingly, a later study identified an interaction between mir-122 and the 5' non-coding region of HCV with inhibition of mir-122 drastically reduced HCV replication (53). Following on from early results, a subsequent group demonstrated that inhibition of mir-122 was effective in reducing cholesterol levels in non-human primates (54). This study used a 15 b.p. locked-nucleic-acid-modified oligonucleotide (LNA-antimir) with the drug name Miravirsen, (Santanis). Using this technology they demonstrated better liver uptake and activity compared to a conventional siRNA. The LNA compound was delivered naked, simplifying siRNA administration as no delivery vector is required. In studies in chronically infected chimpanzees, dosing of $1 \mathrm{mg} / \mathrm{kg}$ or $5 \mathrm{mg} / \mathrm{kg}$ showed a large reduction in HCV viral titres which remained low following drug withdrawal (55). Cholesterol levels were also reduced in the animals, suggesting specific mir122 inhibition was being observed, and miravisen was well tolerated in all groups. The binding site of mir-122 is conserved across all HCV strains, suggesting mir-122 therapy should work in most HCV infections. Miravisen is currently being tested for safety and efficacy in a double blind placebo controlled phase $2 a$ clinical trial. The results of this study are highly anticipated and may demonstrate the first major clinical success of the RNAi field.

\section{HIV}

While silencing of viral genes such as gag was able to treat HIV in cultures $(56,57)$, it was also shown that the virus could rapidly escape siRNA inhibition through mutation (58). Like combinational retroviral therapy, successful inhibition of HIV by siRNA is likely to be only achievable by the simultaneous administration of multiple siRNAs (59). Due to this escape phenomena an attractive alternative approach to 
inhibit of HIV is to target cell surface receptors which mediate viral entry, such as CD4 and CCR5 $(60,61)$. Indeed, homozygotes for a mutation of CCR5 known as the CCR5 532 allele have been shown to have drastically reduced viral susceptibility within an at risk population (62). Recently the bone marrow transplantation of a HIVpositive patient using marrow from a $\operatorname{CCR} 5 \Delta 32$ donor was able to reduce viral load to a level considered curative (63), indicating inhibition of CCR5 is a very attractive strategy. Using either siRNA or lentiviral encoded shRNA a number of groups were able to show HIV infection to be inhibited in macrophages and T-cells via CCR5 or CD4 downregulation by siRNA. While promising results have been observed using aptamers or an anti-CD7 antibody-peptide siRNA conjugate to target and inhibit HIV and CCR5 in T-cells in in vitro studies and humanized mouse models $(64,65)$, the most well progressed therapy has used a lentivirus vector to deliver shRNA to bone marrow cells before transplantation. Lentiviral vectors are an attractive therapy for HIV patients as they can enter haematopoietic stem cells and can express shRNA permanently. The first clinical trial of such a strategy has come from Rossi Group, who developed a lentiviral construct that used shRNA to inhibit CCR5 expression and additionally the tat/rev genes of the virus and a decoy TAR sequence to inhibit HIV polymerase (66). To deliver this lentiviral construct, the group took advantage of a haematopeitic stem cell transplantation that was being undertaken to treat patients for AIDS related lymphoma (67). In this setting patients receive bone marrow transplantations, often of their own cryopreseved CD34+ stem cells, after whole body irradiation to eradicate the lymphoma. A tiny proportion $(0.2 \%)$ of cells were transduced with the lentiviral construct due to safety concerns about the impact of the lentivirus on normal cell function, meaning the impact of the therapy on viral replication was unable to be assessed. However, the group was able to demonstrate 
long term engraftment and expression of the lentivirus in both bone marrow progenitors and blood T-cells, B-cells, and macrophages up to 2 years after engraftment, demonstrating the feasibility of the procedure to safely block viral replication. While a bone marrow transplant is a dangerous and costly procedure, the ability to perform the therapy with a patient's own cells and potential for a cure to HIV means lentiviral delivered shRNA therapy is one of the most promising for AIDS treatment.

\subsection{Immune activation by siRNA}

While overlooked in early studies, it is now well established that siRNA can activate innate immune responses through detection via pattern recognition receptors and lead to production of type 1 interferons IFN- $\alpha$ and IFN- $\beta(68,69)$. Given IFNs' natural antiviral activity, the concept of using this feature of siRNAs to bolster these effects has been explored by several groups including our own. While it has been shown that siRNAs can be modified to activate receptors such as Rig-1 (70) or TLR-9 (71), siRNA is normally recognised by TLR-7 in mice and TLR-7 and 8 in humans (69). The recognition of TLRs by siRNA is sequence specific, with certain sequences such as those which are uridine-rich shown to induce higher responses (72). Interestingly, some viruses are exquisitely sensitive to IFN- $\alpha$, casting doubts on results from early studies using siRNA against viruses. Indeed it was recently shown that modification of siRNA to remove immune stimulation while retaining gene silencing ability removed both in vivo and in vitro effects of an siRNA against influenza $A$ (73). The development of modifications such as the addition of 2'O-methly groups or 2'-fluoro groups to the antisense strand to remove immune activating ability has allowed silencing effects to be separated from immune effects (45). 
While an important consideration in interpreting experimental results using siRNA, the efficacy of immune activating siRNA, however, may result in improved antiviral therapy compared to non immune activating siRNA. The addition of immune activation to siRNA has been shown to improve siRNA potency against of influenza $A$, and human papilloma virus $(17,74)$. As many viruses also dampen interferon- $\alpha$ responses to aid in their survival $(75,76)$, using siRNA to reactivate these responses is likely to assist viral eradication. Like any drug that manipulates the immune system, great care when testing and anticipation of any impact on patient immune system are required when testing siRNA in humans.

\section{RNAi Screening to Identify Novel Antiviral Targets}

A recent tool in the discovery of novel antivirals has been development of large RNAi screens and it is here that the power of RNAi comes to the fore. It is now possible to silence most genes individually within a cell using RNAi. Various RNAi libraries, both shRNA- and siRNA-based, are available and have been used in mass screens to interrogate biology in an unbiased fashion. Such screens have been performed in the presence of virus and have resulted in many previously undiscovered genes being uncovered which are absolutely required for replication. Each new gene represents a new drug target. We have undertaken such a screen using the kinome RNAi subset, that is all the genes that encode for kinases, in order to define new human papillomavirus susceptibility genes. Here we will review and discuss RNAi screening efforts to date. 


\subsection{Screening Technologies}

The concept of the RNAi screen is rather simple - seed cells and transfect them with an RNAi moiety before infecting them with the virus under investigation. Cells that survive, e.g. are not lysed, fused or otherwise infected, must have lost a vital gene required for virus replication. There are two commonly used approaches for RNAi genome-wide screening that utilise either synthetic siRNA libraries (via liposomemediated transduction) or shRNA (via viral transduction). The siRNA lipid-mediated transfection is usually performed in microtiter plates of either 96-or 384-well plate format, where individual genes are knocked down in each well (Figure 2) (77-80). This makes identification of the target gene simple. In contrast, the shRNA method is often performed in a pooled format where the whole library is introduced into the cells and a subsequence selection method (usually PCR based) is then undertaken to identify target genes (81-84). Both methods aim to identify the crucial gene or set of genes that are implicated in the phenotype under investigation and exactly localize the phenotype to the fundamental nodes of a pathway.

Although each method is performed in a different way, both have been used successfully in screens. Moreover, each method has advantages and drawbacks. For instance, in the synthetic siRNA method, the plates can be monitored by cellbased biological assays such as cell lysis, proliferation assays, cytotoxicity assays and/or nucleotide incorporation assays. A major advantage of this 

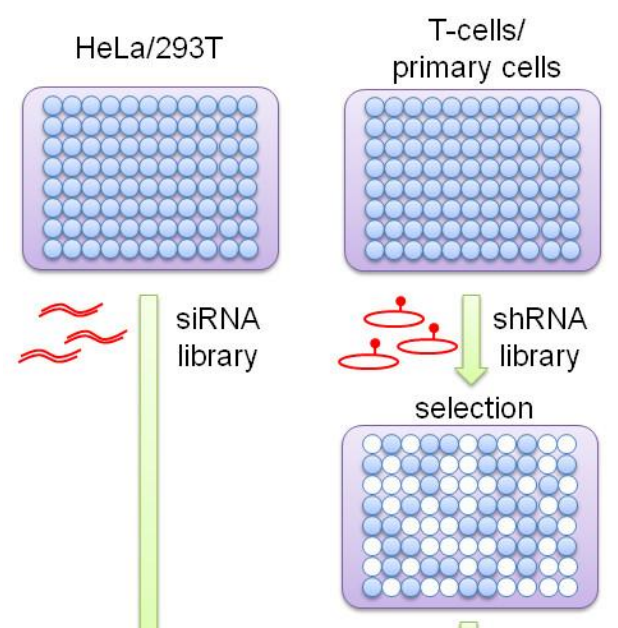

HIV infection

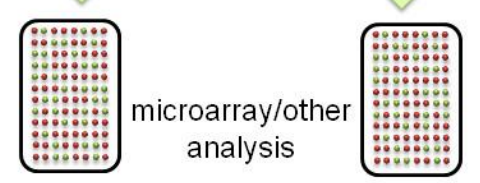

Figure 1. Illustrated diagram of siRNA Vs shRNA to identify HIV host factors required for viral replication. Figure adopted from (85).

method is the multiplexed high-throughput data which can be obtained from each well. Furthermore, the identity of genes is simply allocated by the well ID within the microtiter plates $(80,86-92)$. However, when performing very large-scale screenings, a high number of microtiter plates are needed, and this requires automated platforms to enable reproducibility and avoid variability. Additionally, the method relies on potent cell transfection by siRNA-liposomes and therefore requires easilytransfectable cells, a situation unfavourable for use with primary cells, which are difficult to transfect. On the other hand, viral shRNA can be packaged into a lentiviral vector and used to transduce most cell lines, including primary cells, in a pooled format. It can be stably incorporated into the genome or maintained under drug selection. Using this method it is feasible to introduce genetic material into a broader 
range of dividing and non-dividing cells over longer periods, which is highly advantageous compared to siRNA transfection. Another major advantage of the shRNA method is that it can be performed in simple laboratory settings without the need for expensive automated platforms (81, 85, 93-97). Increasing RNAi investigational findings make it obvious that the RNAi machinery within the human cells has a role in restricting viral infection (98-101). As a result, viruses have developed RNAi suppressors that may act to alter the small non-coding RNA profile in virus infected host cells (102-105).

There are many factors involved in developing a successful screen and these will vary depending on the platform of choice, readout assay and RNAi library chosen. In terms of the screen itself there are three important steps (Figure 2).

\section{Pool of 4 SiRNA targeting each gene}
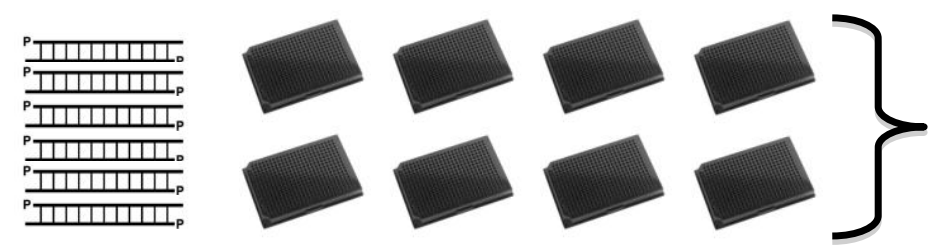

siRNA primary screen

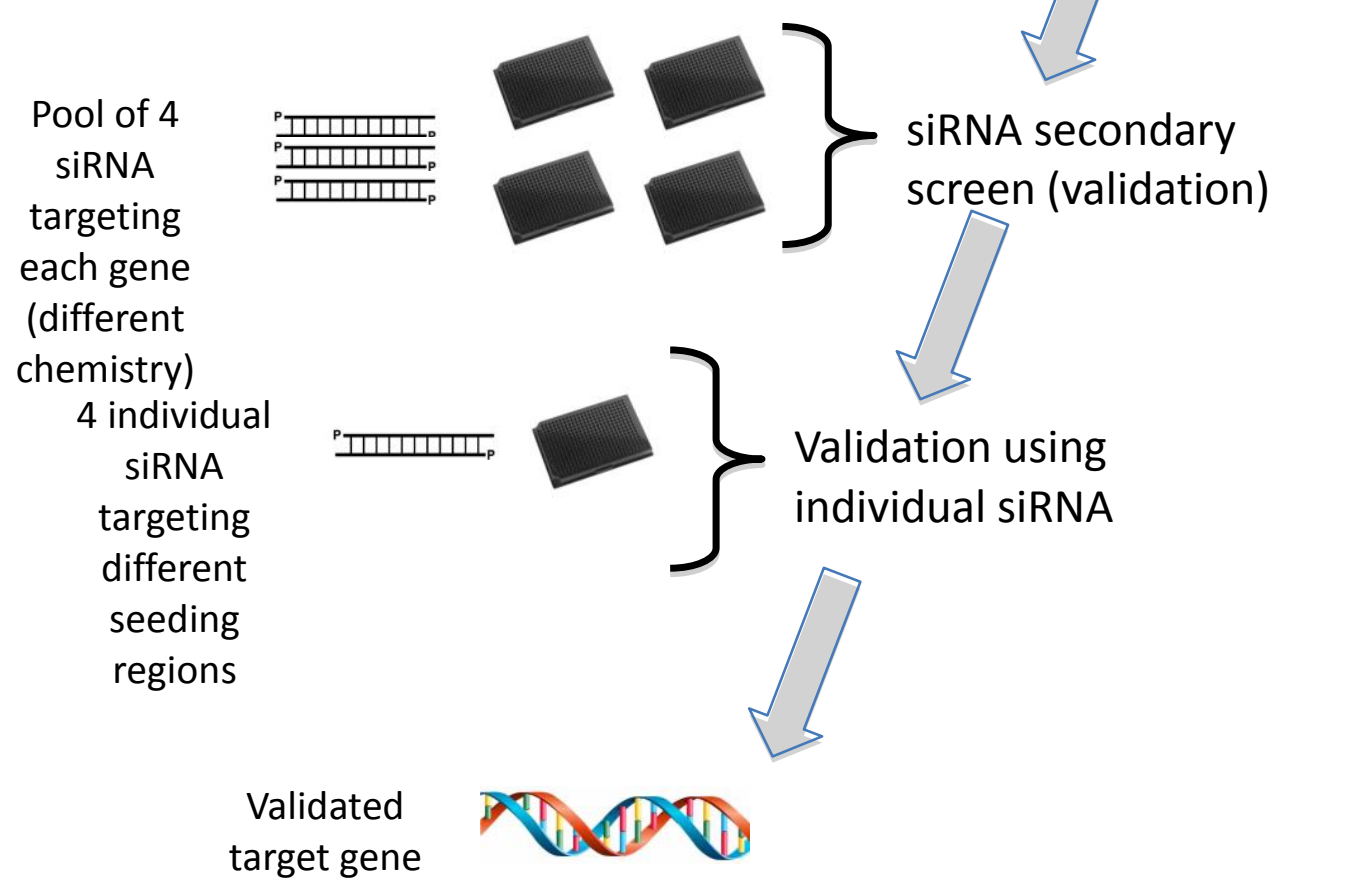


1. The primary screen. Screening of pools or single siRNAs/shRNAs. Often a pool of 4 siRNA/genes is used here (e.g. Dharmacon siGENOME library). Appropriate, multiple controls must be used including positive (eg PLK1) and negative control siRNAs. Starting targets $=1000-30000$

2. A confirmation screen. A repeat of the primary screen target genes that appear interesting from step 1. This ensures inter-screen variation is controlled for. Optionally the 4 siRNA pools can be de-convoluted here to check for specificity. Targets $=100 \mathrm{~s}$

3. A Validation Screen. Re-testing of targets from 1 and 2 using new siRNAs or shRNAs targeted to new regions of the target gene (e.g. Dharmacon ONTargetplus). This will eliminate off-target effects and independently confirm the gene as a bone fide target.

There are have been several recent genome-wide RNAi screens published that have identified novel host factors required for viral replication which we review below.

Human immunodeficiency virus (HIV)

Several RNAi-based screens looking at host factors crucial in the HIV lifecycle have been undertaken. Two of these studies have used different pools of siRNA transfected into engineered HeLa cells expressing viral co-receptor CD4 followed by infection with the virus $(106,107)$. Brass et al investigated both the early and late phases of the HIV lifecycle by looking for p24 (early replication), taking supernatants and incubating them on fresh cells with a Tat-responsive B-galactosidase ( $B-$ Gal) gene to read out viral production. The screen was performed using siRNAs targeting 
21,121 genes. Pools were classified a hit if the activity of the p24 or B-Gal was reduced by more than or equal to two standard deviations (SD) from the plate mean. Another criterion for hit validation was that siRNA should not decrease cell viability by more than two SD. From this, 386 pools met these criteria and were further validated using the four-pooled siRNA in a separated format, resulting in 273 genes identified. Zhou et al used a similar strategy and found 232 genes play some role in HIV replication. Interestingly, only fifteen genes in common were found between these two studies, with seven previously known to be involved in HIV replication including CD4 and CXCR4 (106). A third screen identified 295 genes that also had limited overlap with each of the previous two studies (108).

This lack of overlap appears to be a common theme in RNAi screens and may result from many factors. A meta-analysis looking at the lack of overlap between these three siRNA screens attributed the lack of overlap to experimental noise, differences in sampling time, and variations in hit selection criteria (109). They further calculated that there was only a $50 \%$ chance of the top 300 top hits being obtained in an exactly repeated screen.

A more robust study using Jurkat human T-cells and a lentiviral -shRNA system targeted to 54,509 transcripts was recently undertaken using an endpoint assay of inhibition of virus replication as a readout (110). Of the 54,509 transcripts, only $18.2 \%$ silenced without affecting Jurkat cell viability, and of these, 252 transcripts were identified as important in HIV replication. While these hits demonstrated little overlap with the previously mentioned studies, there was significant overlap in the pathways these genes belonged to, suggesting that RNAi screens do validate in this 
manner and point to potentially useful areas of therapy. Taken together, all four screening studies have identified novel genes which may play crucial roles in HIV replication. Of these, 40 genes were common at least in two screens out of the four studies.

\section{Influenza}

A number genome-wide RNAi screens have been reported in mammalian cells which have uncovered surprising, previously unthought-of, host factors that appear to be essential for influenza replication. Two of these studies have investigated the early and middle phases of the influenza lifecycle $(111,112)$, while the third study considered the complete lifecycle (113). Karlas and colleagues used A549 cells and identified 287 genes required for viral replication. Of these, 119 hits were found to inhibit the H1N1 strain and 121 inhibit the influenza A virus strains originating from swine, with $60 \%$ of theses genes working against both types. For example, they identified DNA SON as an important factor as well as CDC-like kinase 1 (CLK1). Using a small molecule inhibitor against CLK1 reduced the viral replication significantly, showing the importance of this gene for viral replication (113). In another study by Konig et al., the RNAi genome-wide screen revealed 295 cellular factors essential for viral replication. Only 219 hits were confirmed to play crucial roles for influenza virus growth, and subsequent analysis of the data showed 23 genes were important in viral entry. The use of small molecule inhibitors against several factors inhibited viral growth, confirming the importance of these identified target genes (111). In addition, Brass et al identified 121 cellular factors which may contribute to viral replication. For example, they found that interferon-inducible 
transmembrane proteins (IFITM) 1, 2 and 3 constrain an early step of influenza A virus replication. In their study, they point out that IFITM proteins hinder the early replication of flaviviruses such as dengue virus and West Nile virus (112).

Once again these three RNAi genome-wide screens only had 32 genes in common.

West Nile Virus (WNV)

WNV is a member of the Flaviviridae, a family characterized by single-stranded and positive-sense RNA. Krishnan et al used a siRNA-based screen to identify novel cellular factors that are involved in viral replication. HeLa cells were transfected with pools of siRNA and 24 hours post-transfection cells were fixed and viral envelope was measrured by immunofluorescent staining. Hit selection criterion was based on a threshold to 2-fold change in comparison to the controls. Based on this criterion, 305 genes that affect WNV were identified. Of these, 283 genes, when silenced, severely decreased viral gene expression, suggesting that these genes play crucial roles in viral replication. Of these genes, vacuolar ATPase was recognized as a viral replication enhancer.

\section{Dengue Virus (DENV)}

Dengue is an arthropod-borne viral disease with high risk of infection to mankind throughout the globe. Using a genome-wide RNAi screen, Sessions et al screened 22,632 genes in Drosophila melanogaster cells. Only 116 host factors were identified from the screen. Some of these dengue virus host factors (DVHF) had previously been identified as important, such as vacuolar ATPase and $\alpha$-glucosidases, although most of the newly identified DVHF were novel. Sessions et al. identified DVHF which 
were essential for viral replication in human cells, and found that of the original 116 mosquito genes, only 82 were critical in human cells.

Hepatitis $C$ Virus $(\mathrm{HCV})$

To date, there is a lack of selective antiviral therapy or preventive vaccine against HCV and much hope has been placed in genome-wide RNAi screens to identify host factors that are essential for HCV lifecycle. Tai et al identified 96 cellular host factor proteins that are required for $\mathrm{HCV}$ replication, with a remarkable number of these factors being implicated in vesicle organization and biogenesis (114). Among the identified genes, phosphatidylinositol 4-kinase (PI4KA) and COPI vesicle coat complex were tested against some selective small molecule inhibitors. The outcome revealed the inhibition of HCV growth confirming the importance of these host factors for viral replication.

\section{Human papillomavirus (HPV)}

Here at the AID we have undertaken an RNAl screen targeting HPV. HPV is a double-stranded small DNA virus. The virus is subcategorized into two main serotypes, high-risk HPV (HR-HPV) and low-risk HPV (LR-HPV). The HR-HPV is responsible for approximately $99.7 \%$ of cervical cancer cases among women. In our laboratory an siRNA-based screen was carried out on 779 genes from the kinome library on CaSki cells (HPV-16 positive cervical cancer cell line), C33A cells (cervical cancer cell line negative for HPV), and HaCaT cells (spontaneous, immortalized human keratinocytes). Four different cell-based biological assays including cell metabolism, cell cytotoxicity, nucleotide incorporation assay and cell count were used as an endpoint assay for hit selection. Of the 779 kinases, only 55 genes 
demonstrated lethal effect to CaSki when silenced, with minor effect on C33A and HaCaT. A second validation screen was performed to validate these target genes. In the validation screen, two additional cervical cancer cell lines, HeLa (HPV-18 positive) and SiHa (HPV-16 positive) were incorporated. Eight genes showed lethal effect to cervical cancer cell lines with minor effect to HaCaT. Using pharmacological inhibitors, one of these eight genes affected CaSki and HeLa cells' growth in comparison to primary fibroblasts. Papers describing these genes are currently under preparation.

\section{Conclusions of siRNA therapy for viruses}

While siRNA has been long proposed as an excellent clinical tool, early difficulties in delivery has prevented it from reaching its potential. However, with the results of several clinical trials that supposedly demonstrate its effectiveness resulting in less than optimal outcomes, the field awaits true success. Most issues centre around solving the delivery problem. Genome-wide RNAi screening has identified a whole new range of host cell factors currently under investigation. While the screen process itself needs to be carefully worked out and controlled, results are promising ,with many new targets already having small molecule inhibitors ready to use in the clinic. 


\section{References}

1. Jacobs BL, Langland JO, Kibler KV, Denzler KL, White SD, Holechek SA, et al. Vaccinia virus vaccines: past, present and future. Antiviral research. [Historical Article Review]. 2009 Oct;84(1):1-13.

2. Progress toward poliomyelitis eradication --- afghanistan and pakistan, january 2010-september 2011. MMWR Morbidity and mortality weekly report. 2011 Nov 11;60:1523-7.

3. Read TR, Hocking JS, Chen MY, Donovan B, Bradshaw CS, Fairley CK. The near disappearance of genital warts in young women 4 years after commencing a national human papillomavirus (HPV) vaccination programme. Sexually transmitted infections. 2011 Dec;87(7):544-7.

4. Donovan B, Grulich AE. The quadrivalent HPV vaccine is effective prophylaxis against HPV-related external genital lesions in young men. Evidence-based medicine. [Comment]. 2011 Oct;16(5):157-8.

5. Munier CM, Andersen CR, Kelleher AD. HIV vaccines: progress to date. Drugs. [Research Support, Non-U.S. Gov't

Review]. 2011 Mar 5;71(4):387-414.

6. Collins PL, Melero JA. Progress in understanding and controlling respiratory syncytial virus: Still crazy after all these years. Virus research. 2011 Dec;162(1-2):80-99.

7. Jackson RJ, Cooper KL, Tappenden P, Rees A, Simpson EL, Read RC, et al. Oseltamivir, zanamivir and amantadine in the prevention of influenza: a systematic review. The Journal of infection. [Meta-Analysis

Research Support, Non-U.S. Gov't

Review]. 2011 Jan;62(1):14-25.

8. Elbashir SM, Harborth J, Lendeckel W, Yalcin A, Weber K, Tuschl T. Duplexes of 21-nucleotide RNAs mediate RNA interference in cultured mammalian cells. Nature. 2001;411(6836):494-8.

9. Fire A, Xu S, Montgomery MK, Kostas SA, Driver SE, Mello CC. Potent and specific genetic interference by double-stranded RNA in Caenorhabditis elegans. Nature. 1998 Feb 19;391(6669):806-11.

10. Napoli C, Lemieux C, Jorgensen R. Introduction of a Chimeric Chalcone Synthase Gene into Petunia Results in Reversible Co-Suppression of Homologous Genes in trans. The Plant cell. 1990 Apr;2(4):279-89.

11. Waterhouse PM, Graham MW, Wang MB. Virus resistance and gene silencing in plants can be induced by simultaneous expression of sense and antisense RNA. Proceedings of the National Academy of Sciences of the United States of America. 1998 Nov 10;95(23):13959-64.

12. Voinnet O, Baulcombe DC. Systemic signalling in gene silencing. Nature. [Letter]. 1997 Oct 9;389(6651):553.

13. Novina CD, Murray MF, Dykxhoorn DM, Beresford PJ, Riess J, Lee SK, et al. siRNA-directed inhibition of HIV-1 infection. Nature medicine. [Research Support, U.S. Gov't, P.H.S.]. 2002 Jul;8(7):681-6.

14. Voinnet $O$. Induction and suppression of RNA silencing: insights from viral infections. Nature reviews Genetics. [Research Support, Non-U.S. Gov't

Review]. 2005 Mar;6(3):206-20.

15. Tompkins SM, Lo CY, Tumpey TM, Epstein SL. Protection against lethal influenza virus challenge by RNA interference in vivo. Proc Natl Acad Sci U S A. 2004 Jun 8;101(23):8682-6. 
16. Ge Q, Filip L, Bai A, Nguyen T, Eisen HN, Chen J. Inhibition of influenza virus production in virus-infected mice by RNA interference. Proc Natl Acad Sci U S A. 2004 Jun 8;101(23):8676-81.

17. Stewart CR, Karpala AJ, Lowther S, Lowenthal JW, Bean AG. Immunostimulatory motifs enhance antiviral siRNAs targeting highly pathogenic avian influenza H5N1. PLoS One. 2011;6(7):e21552.

18. Qin ZL, Zhao P, Cao MM, Qi ZT. siRNAs targeting terminal sequences of the SARSassociated coronavirus membrane gene inhibit $\mathrm{M}$ protein expression through degradation of M mRNA. J Virol Methods. 2007 Nov;145(2):146-54.

19. Li BJ, Tang Q, Cheng D, Qin C, Xie FY, Wei Q, et al. Using siRNA in prophylactic and therapeutic regimens against SARS coronavirus in Rhesus macaque. Nat Med. 2005 Sep;11(9):944-51.

20. Zhang Y, Li T, Fu L, Yu C, Li Y, Xu X, et al. Silencing SARS-CoV Spike protein expression in cultured cells by RNA interference. FEBS Lett. 2004 Feb 27;560(1-3):141-6.

21. Tang Q, Li B, Woodle M, Lu PY. Application of siRNA against SARS in the rhesus macaque model. Methods Mol Biol. 2008;442:139-58.

22. Wu SY, Singhania A, Burgess M, Putral LN, Kirkpatrick C, Davies NM, et al. Systemic delivery of E6/7 siRNA using novel lipidic particles and its application with cisplatin in cervical cancer mouse models. Gene Ther. 2011 Jan;18(1):14-22.

23. Putral LN, Bywater MJ, Gu W, Saunders NA, Gabrielli BG, Leggatt GR, et al. RNA interference against human papillomavirus oncogenes in cervical cancer cells results in increased sensitivity to cisplatin. Mol Pharmacol. 2005 Nov;68(5):1311-9.

24. Jiang M, Milner J. Selective silencing of viral gene expression in HPV-positive human cervical carcinoma cells treated with siRNA, a primer of RNA interference. Oncogene. 2002 Sep 5;21(39):6041-8.

25. Yin Q, Flemington EK. siRNAs against the Epstein Barr virus latency replication factor, EBNA1, inhibit its function and growth of EBV-dependent tumor cells. Virology. 2006 Mar 15;346(2):385-93.

26. Hong M, Murai $\mathrm{Y}$, Kutsuna $\mathrm{T}$, Takahashi $\mathrm{H}$, Nomoto $\mathrm{K}$, Cheng $\mathrm{CM}$, et al. Suppression of Epstein-Barr nuclear antigen 1 (EBNA1) by RNA interference inhibits proliferation of EBV-positive Burkitt's lymphoma cells. J Cancer Res Clin Oncol. 2006 Jan;132(1):1-8.

27. Geisbert TW, Lee AC, Robbins M, Geisbert JB, Honko AN, Sood V, et al. Postexposure protection of non-human primates against a lethal Ebola virus challenge with RNA interference: a proof-of-concept study. Lancet. 2010 May 29;375(9729):1896-905.

28. Geisbert TW, Hensley LE, Kagan E, Yu EZ, Geisbert JB, Daddario-DiCaprio K, et al. Postexposure protection of guinea pigs against a lethal ebola virus challenge is conferred by RNA interference. J Infect Dis. 2006 Jun 15;193(12):1650-7.

29. Falsey AR, Hennessey PA, Formica MA, Cox C, Walsh EE. Respiratory syncytial virus infection in elderly and high-risk adults. N Engl J Med. 2005 Apr 28;352(17):1749-59.

30. Thompson WW, Shay DK, Weintraub E, Brammer L, Cox N, Anderson LJ, et al. Mortality associated with influenza and respiratory syncytial virus in the United States. JAMA. 2003 Jan 8;289(2):179-86.

31. Zhang W, Yang H, Kong X, Mohapatra S, San Juan-Vergara H, Hellermann G, et al. Inhibition of respiratory syncytial virus infection with intranasal siRNA nanoparticles targeting the viral NS1 gene. Nat Med. 2005 Jan;11(1):56-62.

32. Bitko V, Musiyenko A, Shulyayeva O, Barik S. Inhibition of respiratory viruses by nasally administered siRNA. Nat Med. 2005 Jan;11(1):50-5. 
33. Jin H, Zhou H, Cheng X, Tang R, Munoz M, Nguyen N. Recombinant respiratory syncytial viruses with deletions in the NS1, NS2, SH, and M2-2 genes are attenuated in vitro and in vivo. Virology. $2000 \mathrm{Jul} 20 ; 273(1): 210-8$.

34. Lo MS, Brazas RM, Holtzman MJ. Respiratory syncytial virus nonstructural proteins NS1 and NS2 mediate inhibition of Stat2 expression and alpha/beta interferon responsiveness. J Virol. 2005 Jul;79(14):9315-9.

35. Bitko V, Barik S. Phenotypic silencing of cytoplasmic genes using sequence-specific double-stranded short interfering RNA and its application in the reverse genetics of wild type negative-strand RNA viruses. BMC Microbiol. 2001;1:34.

36. DeVincenzo J, Cehelsky JE, Alvarez R, Elbashir S, Harborth J, Toudjarska I, et al. Evaluation of the safety, tolerability and pharmacokinetics of ALN-RSV01, a novel RNAi antiviral therapeutic directed against respiratory syncytial virus (RSV). Antiviral Res. 2008 Mar;77(3):225-31.

37. DeVincenzo J, Lambkin-Williams R, Wilkinson T, Cehelsky J, Nochur S, Walsh E, et al. A randomized, double-blind, placebo-controlled study of an RNAi-based therapy directed against respiratory syncytial virus. Proc Natl Acad Sci U S A. 2010 May 11;107(19):8800-5.

38. Kao JH, Chen DS. Global control of hepatitis B virus infection. Lancet Infect Dis. 2002 Jul;2(7):395-403.

39. WHO. Hepatitis B virus Fact sheet No. 204 (Revised 2008). . 2008.

40. de Wolf HK, Snel CJ, Verbaan FJ, Schiffelers RM, Hennink WE, Storm G. Effect of cationic carriers on the pharmacokinetics and tumor localization of nucleic acids after intravenous administration. Int J Pharm. 2007 Mar 1;331(2):167-75.

41. Gao S, Chen J, Dong L, Ding Z, Yang YH, Zhang J. Targeting delivery of oligonucleotide and plasmid DNA to hepatocyte via galactosylated chitosan vector. Eur J Pharm Biopharm. 2005 Aug;60(3):327-34.

42. Shlomai A, Shaul Y. Inhibition of hepatitis B virus expression and replication by RNA interference. Hepatology. 2003 Apr;37(4):764-70.

43. Kapadia SB, Brideau-Andersen A, Chisari FV. Interference of hepatitis $\mathrm{C}$ virus RNA replication by short interfering RNAs. Proc Natl Acad Sci U S A. 2003 Feb 18;100(4):20148.

44. Morrissey DV, Lockridge JA, Shaw L, Blanchard K, Jensen K, Breen W, et al. Potent and persistent in vivo anti-HBV activity of chemically modified siRNAs. Nat Biotechnol. 2005 Aug;23(8):1002-7.

45. Morrissey DV, Blanchard K, Shaw L, Jensen K, Lockridge JA, Dickinson B, et al. Activity of stabilized short interfering RNA in a mouse model of hepatitis B virus replication. Hepatology. 2005 Jun;41(6):1349-56.

46. Giering JC, Grimm D, Storm TA, Kay MA. Expression of shRNA from a tissuespecific pol II promoter is an effective and safe RNAi therapeutic. Mol Ther. 2008 Sep;16(9):1630-6.

47. Chen CC, Ko TM, Ma HI, Wu HL, Xiao X, Li J, et al. Long-term inhibition of hepatitis B virus in transgenic mice by double-stranded adeno-associated virus 8-delivered short hairpin RNA. Gene Ther. 2007 Jan;14(1):11-9.

48. Gish RG, Satishchandran C, Young M, Pachuk C. RNA interference and its potential applications to chronic HBV treatment: results of a Phase I safety and tolerability study. Antivir Ther. 2011;16(4):547-54.

49. Bostan N, Mahmood T. An overview about hepatitis C: a devastating virus. Crit Rev Microbiol. 2010 May;36(2):91-133.

50. Lagos-Quintana M, Rauhut R, Yalcin A, Meyer J, Lendeckel W, Tuschl T. Identification of tissue-specific microRNAs from mouse. Curr Biol. 2002 Apr 30;12(9):7359. 
51. Esau C, Davis S, Murray SF, Yu XX, Pandey SK, Pear M, et al. miR-122 regulation of lipid metabolism revealed by in vivo antisense targeting. Cell Metab. 2006 Feb;3(2):87-98. 52. Chang J, Nicolas E, Marks D, Sander C, Lerro A, Buendia MA, et al. miR-122, a mammalian liver-specific microRNA, is processed from hor mRNA and may downregulate the high affinity cationic amino acid transporter CAT-1. RNA Biol. 2004 Jul;1(2):106-13.

53. Jopling CL, Yi M, Lancaster AM, Lemon SM, Sarnow P. Modulation of hepatitis C virus RNA abundance by a liver-specific MicroRNA. Science. 2005 Sep 2;309(5740):157781.

54. Elmen J, Lindow M, Schutz S, Lawrence M, Petri A, Obad S, et al. LNA-mediated microRNA silencing in non-human primates. Nature. 2008 Apr 17;452(7189):896-9.

55. Lanford RE, Hildebrandt-Eriksen ES, Petri A, Persson R, Lindow M, Munk ME, et al. Therapeutic silencing of microRNA-122 in primates with chronic hepatitis $\mathrm{C}$ virus infection. Science. 2010 Jan 8;327(5962):198-201.

56. Novina CD, Murray MF, Dykxhoorn DM, Beresford PJ, Riess J, Lee SK, et al. siRNA-directed inhibition of HIV-1 infection. Nat Med. 2002 Jul;8(7):681-6.

57. Capodici J, Kariko K, Weissman D. Inhibition of HIV-1 infection by small interfering RNA-mediated RNA interference. J Immunol. 2002 Nov 1;169(9):5196-201.

58. Das AT, Brummelkamp TR, Westerhout EM, Vink M, Madiredjo M, Bernards R, et al. Human immunodeficiency virus type 1 escapes from RNA interference-mediated inhibition. J Virol. 2004 Mar;78(5):2601-5.

59. ter Brake O, t Hooft K, Liu YP, Centlivre M, von Eije KJ, Berkhout B. Lentiviral vector design for multiple shRNA expression and durable HIV-1 inhibition. Mol Ther. 2008 Mar;16(3):557-64.

60. Dragic T, Litwin V, Allaway GP, Martin SR, Huang Y, Nagashima KA, et al. HIV-1 entry into CD4+ cells is mediated by the chemokine receptor CC-CKR-5. Nature. 1996 Jun 20;381(6584):667-73.

61. Dalgleish AG, Beverley PC, Clapham PR, Crawford DH, Greaves MF, Weiss RA. The CD4 (T4) antigen is an essential component of the receptor for the AIDS retrovirus. Nature. 1984 Dec 20-1985 Jan 2;312(5996):763-7.

62. Huang Y, Paxton WA, Wolinsky SM, Neumann AU, Zhang L, He T, et al. The role of a mutant CCR5 allele in HIV-1 transmission and disease progression. Nat Med. 1996 Nov;2(11):1240-3.

63. Hutter G, Nowak D, Mossner M, Ganepola S, Mussig A, Allers K, et al. Long-term control of HIV by CCR5 Delta32/Delta32 stem-cell transplantation. N Engl J Med. 2009 Feb 12;360(7):692-8.

64. Neff CP, Zhou J, Remling L, Kuruvilla J, Zhang J, Li H, et al. An aptamer-siRNA chimera suppresses HIV-1 viral loads and protects from helper CD4(+) T cell decline in humanized mice. Sci Transl Med. 2011 Jan 19;3(66):66ra6.

65. Kumar P, Ban HS, Kim SS, Wu H, Pearson T, Greiner DL, et al. T cell-specific siRNA delivery suppresses HIV-1 infection in humanized mice. Cell. 2008 Aug 22;134(4):577-86.

66. Li MJ, Kim J, Li S, Zaia J, Yee JK, Anderson J, et al. Long-term inhibition of HIV-1 infection in primary hematopoietic cells by lentiviral vector delivery of a triple combination of anti-HIV shRNA, anti-CCR5 ribozyme, and a nucleolar-localizing TAR decoy. Mol Ther. 2005 Nov;12(5):900-9.

67. DiGiusto DL, Krishnan A, Li L, Li H, Li S, Rao A, et al. RNA-based gene therapy for HIV with lentiviral vector-modified CD34(+) cells in patients undergoing transplantation for AIDS-related lymphoma. Sci Transl Med. 2010 Jun 16;2(36):36ra43. 
68. Judge AD, Sood V, Shaw JR, Fang D, McClintock K, MacLachlan I. Sequencedependent stimulation of the mammalian innate immune response by synthetic siRNA. Nat Biotechnol. 2005 Apr;23(4):457-62.

69. Hornung V, Guenthner-Biller M, Bourquin C, Ablasser A, Schlee M, Uematsu S, et al. Sequence-specific potent induction of IFN-alpha by short interfering RNA in plasmacytoid dendritic cells through TLR7. Nat Med. 2005 Mar;11(3):263-70.

70. Poeck H, Besch R, Maihoefer C, Renn M, Tormo D, Morskaya SS, et al. 5'Triphosphate-siRNA: turning gene silencing and Rig-I activation against melanoma. Nat Med. 2008 Nov;14(11):1256-63.

71. Kortylewski M, Swiderski P, Herrmann A, Wang L, Kowolik C, Kujawski M, et al. In vivo delivery of siRNA to immune cells by conjugation to a TLR9 agonist enhances antitumor immune responses. Nat Biotechnol. 2009 Oct;27(10):925-32.

72. Gantier MP, Tong S, Behlke MA, Irving AT, Lappas M, Nilsson UW, et al. Rational design of immunostimulatory siRNAs. Mol Ther. 2010 Apr;18(4):785-95.

73. Robbins M, Judge A, Ambegia E, Choi C, Yaworski E, Palmer L, et al. Misinterpreting the therapeutic effects of small interfering RNA caused by immune stimulation. Hum Gene Ther. 2008 Oct;19(10):991-9.

74. Khairuddin N, Gantier MP, Blake SJ, Wu SY, Behlke MA, Williams BR, et al. siRNA-induced immunostimulation through TLR7 promotes antitumoral activity against HPV-driven tumors in vivo. Immunol Cell Biol. 2011 Mar 22.

75. Min JY, Li S, Sen GC, Krug RM. A site on the influenza A virus NS1 protein mediates both inhibition of PKR activation and temporal regulation of viral RNA synthesis. Virology. 2007 Jun 20;363(1):236-43.

76. Li XD, Sun L, Seth RB, Pineda G, Chen ZJ. Hepatitis C virus protease NS3/4A cleaves mitochondrial antiviral signaling protein off the mitochondria to evade innate immunity. Proc Natl Acad Sci U S A. 2005 Dec 6;102(49):17717-22.

77. Henderson MC, Gonzales IM, Arora S, Choudhary A, Trent JM, Von Hoff DD, et al. High-throughput RNAi screening identifies a role for TNK1 in growth and survival of pancreatic cancer cells. Mol Cancer Res. 2011 Jun;9(6):724-32.

78. Choudhary S, Rosenblatt KP, Fang L, Tian B, Wu ZH, Brasier AR. High throughput short interfering RNA (siRNA) screening of the human kinome identifies novel kinases controlling the canonical nuclear factor-kappaB (NF-kappaB) activation pathway. J Biol Chem. 2011 Oct 28;286(43):37187-95.

79. Babij C, Zhang Y, Kurzeja RJ, Munzli A, Shehabeldin A, Fernando M, et al. STK33 kinase activity is nonessential in KRAS-dependent cancer cells. Cancer Res. 2011 Sep 1;71(17):5818-26.

80. Lara R, Mauri FA, Taylor H, Derua R, Shia A, Gray C, et al. An siRNA screen identifies RSK1 as a key modulator of lung cancer metastasis. Oncogene. 2011 Aug 11;30(32):3513-21.

81. Bayona-Bafaluy MP, Sanchez-Cabo F, Fernandez-Silva P, Perez-Martos A, Enriquez JA. A genome-wide shRNA screen for new OxPhos related genes. Mitochondrion. 2011 May;11(3):467-75.

82. Sims D, Mendes-Pereira AM, Frankum J, Burgess D, Cerone MA, Lombardelli $\mathrm{C}$, et al. High-throughput RNA interference screening using pooled shRNA libraries and next generation sequencing. Genome Biol. 2011 Oct 21;12(10):R104.

83. Krastev DB, Slabicki M, Paszkowski-Rogacz M, Hubner NC, Junqueira M, Shevchenko A, et al. A systematic RNAi synthetic interaction screen reveals a link between p53 and snoRNP assembly. Nat Cell Biol. 2011 Jul;13(7):809-18. 
84. Wilson BA, Wang H, Nacev BA, Mease RC, Liu JO, Pomper MG, et al. Highthroughput screen identifies novel inhibitors of cancer biomarker alpha-methylacyl coenzyme A racemase (AMACR/P504S). Mol Cancer Ther. 2011 May;10(5):825-38.

85. Kok KH, Lei T, Jin DY. siRNA and shRNA screens advance key understanding of host factors required for HIV-1 replication. Retrovirology. 2009;6:78.

86. Menzel T, Nahse-Kumpf V, Kousholt AN, Klein DK, Lund-Andersen C, Lees M, et al. A genetic screen identifies BRCA2 and PALB2 as key regulators of $\mathrm{G} 2$ checkpoint maintenance. EMBO Rep. 2011 Jul;12(7):705-12.

87. Thaker NG, McDonald PR, Zhang F, Kitchens CA, Shun TY, Pollack IF, et al. Designing, optimizing, and implementing high-throughput siRNA genomic screening with glioma cells for the discovery of survival genes and novel drug targets. J Neurosci Methods. 2010 Jan 15;185(2):204-12.

88. Lord CJ, McDonald S, Swift S, Turner NC, Ashworth A. A high-throughput RNA interference screen for DNA repair determinants of PARP inhibitor sensitivity. DNA Repair (Amst). 2008 Dec 1;7(12):2010-9.

89. Poon SS, Wong JT, Saunders DN, Ma QC, McKinney S, Fee J, et al. Intensity calibration and automated cell cycle gating for high-throughput image-based siRNA screens of mammalian cells. Cytometry A. 2008 Oct;73(10):904-17.

90. Whitehurst AW, Bodemann BO, Cardenas J, Ferguson D, Girard L, Peyton M, et al. Synthetic lethal screen identification of chemosensitizer loci in cancer cells. Nature. 2007 Apr 12;446(7137):815-9.

91. Llanos S, Efeyan A, Monsech J, Dominguez O, Serrano M. A high-throughput lossof-function screening identifies novel p53 regulators. Cell Cycle. 2006 Aug;5(16):1880-5.

92. Hsieh AC, Bo R, Manola J, Vazquez F, Bare O, Khvorova A, et al. A library of siRNA duplexes targeting the phosphoinositide 3-kinase pathway: determinants of gene silencing for use in cell-based screens. Nucleic Acids Res. 2004;32(3):893-901.

93. Prusty BK, Karlas A, Meyer TF, Rudel T. Genome-wide RNAi screen for viral replication in mammalian cell culture. Methods Mol Biol. 2011;721:383-95.

94. Colombi M, Molle KD, Benjamin D, Rattenbacher-Kiser K, Schaefer C, Betz C, et al. Genome-wide shRNA screen reveals increased mitochondrial dependence upon mTORC2 addiction. Oncogene. 2011 Mar 31;30(13):1551-65.

95. Hu G, Kim J, Xu Q, Leng Y, Orkin SH, Elledge SJ. A genome-wide RNAi screen identifies a new transcriptional module required for self-renewal. Genes Dev. 2009 Apr $1 ; 23(7): 837-48$.

96. Ossovskaya VS, Dolganov G, Basbaum AI. Loss of function genetic screens reveal MTGR1 as an intracellular repressor of beta1 integrin-dependent neurite outgrowth. J Neurosci Methods. 2009 Mar 15;177(2):322-33.

97. Gobeil S, Zhu X, Doillon CJ, Green MR. A genome-wide shRNA screen identifies GAS1 as a novel melanoma metastasis suppressor gene. Genes Dev. 2008 Nov 1;22(21):2932-40.

98. Song L, Liu H, Gao S, Jiang W, Huang W. Cellular microRNAs inhibit replication of the $\mathrm{H} 1 \mathrm{~N} 1$ influenza $A$ virus in infected cells. J Virol. 2010 Sep;84(17):8849-60.

99. Wang X, Ye L, Hou W, Zhou Y, Wang YJ, Metzger DS, et al. Cellular microRNA expression correlates with susceptibility of monocytes/macrophages to HIV-1 infection. Blood. 2009 Jan 15;113(3):671-4.

100. Nathans R, Chu CY, Serquina AK, Lu CC, Cao H, Rana TM. Cellular microRNA and P bodies modulate host-HIV-1 interactions. Mol Cell. 2009 Jun 26;34(6):696-709. 
101. Huang J, Wang F, Argyris E, Chen K, Liang Z, Tian H, et al. Cellular microRNAs contribute to HIV-1 latency in resting primary CD4+ T lymphocytes. Nat Med. 2007 Oct;13(10):1241-7.

102. Schnettler E, de Vries W, Hemmes H, Haasnoot J, Kormelink R, Goldbach R, et al. The NS3 protein of rice hoja blanca virus complements the RNAi suppressor function of HIV-1 Tat. EMBO Rep. 2009 Mar;10(3):258-63.

103. de Vries W, Haasnoot J, Fouchier R, de Haan P, Berkhout B. Differential RNA silencing suppression activity of NS1 proteins from different influenza A virus strains. J Gen Virol. 2009 Aug;90(Pt 8):1916-22.

104. de Vries W, Berkhout B. RNAi suppressors encoded by pathogenic human viruses. Int J Biochem Cell Biol. 2008;40(10):2007-12.

105. J Haasnoot, de Vries W, Geutjes EJ, Prins M, de Haan P, B. B. The Ebola virus VP35 protein is a suppressor of RNA silencing. PLoS Pathog. 2007;3(6):e86.

106. Zhou H, Xu M, Huang Q, Gates AT, Zhang XD, Castle JC, et al. Genome-scale RNAi screen for host factors required for HIV replication. Cell Host Microbe. 2008 Nov 13;4(5):495-504.

107. Brass AL, Dykxhoorn DM, Benita Y, Yan N, Engelman A, Xavier RJ, et al. Identification of host proteins required for HIV infection through a functional genomic screen. Science. 2008 Feb 15;319(5865):921-6.

108. R König, Zhou Y, Elleder D, Diamond TL, Bonamy GM, Irelan JT, et al. Global analysis of host-pathogen interactions that regulate early-stage HIV-1 replication. Cell. 2008;135(1):49-60.

109. Bushman FD, Malani N, Fernandes J, D'Orso I, Cagney G, Diamond TL, et al. Host cell factors in HIV replication: meta-analysis of genome-wide studies. PLoS Pathog. 2009 May;5(5):e1000437.

110. Yeung ML, Houzet L, Yedavalli VS, Jeang KT. A genome-wide short hairpin RNA screening of jurkat T-cells for human proteins contributing to productive HIV-1 replication. J Biol Chem. 2009 Jul 17;284(29):19463-73.

111. Konig R, Stertz S, Zhou Y, Inoue A, Hoffmann HH, Bhattacharyya S, et al. Human host factors required for influenza virus replication. Nature. 2010 Feb 11;463(7282):813-7.

112. Brass AL, Huang IC, Benita Y, John SP, Krishnan MN, Feeley EM, et al. The IFITM proteins mediate cellular resistance to influenza A H1N1 virus, West Nile virus, and dengue virus. Cell. 2009 Dec 24;139(7):1243-54.

113. Karlas A, Machuy N, Shin Y, Pleissner KP, Artarini A, Heuer D, et al. Genomewide RNAi screen identifies human host factors crucial for influenza virus replication. Nature. 2010 Feb 11;463(7282):818-22.

114. Tai AW, Benita Y, Peng LF, Kim SS, Sakamoto N, Xavier RJ, et al. A functional genomic screen identifies cellular cofactors of hepatitis $\mathrm{C}$ virus replication. Cell host \& microbe. [Research Support, N.I.H., Extramural

Research Support, Non-U.S. Gov't]. 2009 Mar 19;5(3):298-307. 